\title{
The role of novel biomarkers in predicting diabetic nephropathy: a review
}

\section{Samuel N Uwaezuoke \\ Pediatric Nephrology Firm, Department of Pediatrics, University of Nigeria Teaching Hospital, Ituku- Ozalla, Enugu, Nigeria}

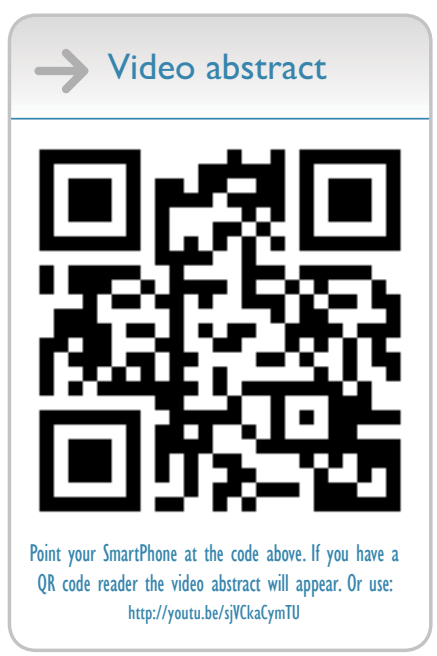

Correspondence: Samuel N Uwaezuoke Department of Pediatrics, University of Nigeria Teaching Hospital, Ituku-Ozalla, PMB 02219 Enugu, 40000I, Nigeria

$\mathrm{Tel}+2348033248108$

Email snuwaezuoke@yahoo.com
This article was published in the following Dove Press journal: International Journal of Nephrology and Renovascular Disease 17 August 2017

Number of times this article has been viewed

\begin{abstract}
Diabetic nephropathy (DN) is one of the microvascular complications of the kidney arising commonly from type 1 diabetes mellitus (T1DM), and occasionally from type 2 diabetes mellitus (T2DM). Microalbuminuria serves as an early indicator of DN risk and a predictor of its progression as well as cardiovascular disease risk in both T1DM and T2DM. Although microalbuminuria remains the gold standard for early detection of $\mathrm{DN}$, it is not a sufficiently accurate predictor of DN risk due to some limitations. Thus, there is a paradigm shift to novel biomarkers which would help to predict DN risk early enough and possibly prevent the occurrence of end-stage kidney disease. These new biomarkers have been broadly classified into glomerular biomarkers, tubular biomarkers, biomarkers of inflammation, biomarkers of oxidative stress, and miscellaneous biomarkers which also include podocyte biomarkers, some of which are also considered as tubular and glomerular biomarkers. Although they are potentially useful for the evaluation of DN, current data still preclude the routine clinical use of majority of them. However, their validation using high-quality and large longitudinal studies is of paramount importance, as well as the subsequent development of a biomarker panel which can reliably predict and evaluate this renal microvascular disease. This paper aims to review the predictive role of these biomarkers in the evaluation of DN.
\end{abstract}

Keywords: type 1 diabetes mellitus, renal microvascular complication, microalbuminuria, end-stage kidney disease, biomarker panel

\section{Introduction}

Diabetic nephropathy (DN) is one of the renal microvascular complications which is commonly due to type 1 diabetes mellitus (T1DM), and occasionally due to type 2 diabetes mellitus (T2DM). ${ }^{1-3}$ It is a clinical syndrome comprising the following features: persistent albuminuria (or albuminuria excretion rate of $>300 \mathrm{mg} / \mathrm{d}$ or $200 \mu \mathrm{g}$ / min) recorded at least twice within a 3- to 6-month interval, progressive reduction in glomerular filtration rate (GFR), and hypertension. ${ }^{3}$ The evolution of DN occurs over a period of 10-20 years, beginning from microalbuminuria and progressing to end-stage kidney disease (ESKD). ${ }^{1}$ Thus, overt $\mathrm{DN}$ is very rare in the pediatric age group, ${ }^{4}$ although some previous reports have confirmed its occurrence in childhood. ${ }^{5-7}$ Notably, patients with DN and T1DM almost always present with other signs of diabetic microvascular disease such as retinopathy and neuropathy; in fact, retinopathy usually precedes the onset of overt DN in these patients. ${ }^{2}$

Glomerular hyperfiltration occurs in the early stage of DN resulting in microalbuminuria. As the disease progresses, macroalbuminuria sets in and is followed by 
deterioration in renal function and ESKD, which may eventually require renal replacement therapy. ${ }^{8}$ Microalbuminuria therefore serves not only as an indicator of DN risk but also as a strong predictor of its progression, and a predictor of cardiovascular disease risk in both T1DM and T2DM. ${ }^{2}$ For instance, $80 \%$ of T1DM patients with microalbuminuria will end up with overt nephropathy (macroalbuminuria) within 10-15 years, $50 \%$ of whom will develop ESKD within 10 years and $75 \%$ within 20 years if there are no appropriate therapeutic interventions. ${ }^{9}$ However, subsequent studies have disputed these previous observations. ${ }^{10-12}$ It is now projected that the rate of progression from microalbuminuria to macroalbuminuria over a 5 - to 10 -year period is about $15-30 \%$, although as high as $45 \%$ in patients with less than 15 years of diabetes duration but much lower than the initially estimated figure of $80 \% .^{13}$

Although microalbuminuria remains the gold standard marker for early detection of DN, it is not a sufficiently accurate predictor of DN risk given some limitations. For example, not all diabetics with microalbuminuria will end up with $\mathrm{ESKD}^{8,14}$ and $30 \%$ of them may actually have normoalbuminuria, ${ }^{15}$ while several biomarkers of glomerular or tubular dysfunction can precede microalbuminuria, suggesting that microalbuminuria is present once significant renal injury has already occurred. ${ }^{16}$ Nevertheless, its predictive accuracy can be enhanced by other parameters such as a painstaking family history, consideration of absolute versus categorical urine albumin excretion (UAE) values, more frequent UAE estimates, ambulatory blood pressure monitoring, precise GFR measurements, diabetic retinopathy assessments, and plasma lipid profile. ${ }^{13}$ Interestingly, there is now a paradigm shift to novel biomarkers which would help to predict DN risk early enough, and possibly prevent the occurrence of ESKD. This paper aims to review the predictive role of these biomarkers in the evaluation of DN.

\section{Pathogenesis of DN: overview of molecular mechanisms}

Recent observations indicate that several pathways are activated during the development of diabetes mellitus; these pathways individually or collectively modulate the induction and progression of $\mathrm{DN} .{ }^{17}$ Although the pathogenesis of $\mathrm{DN}$ is multifactorial, the mechanisms that propel its development remain largely unclear. ${ }^{17,18}$ During the course of DN, the functional derangement and structural remodeling of the kidney, triggered by hyperglycemic injury, are linked to changes in several cellular events and activation of signaling pathways. ${ }^{19}$

These pathways interact in a cascade of complex molecular mechanisms, resulting in the major pathogenic components of DN, which consist of renal fibrosis, mesangial expansion, glomerular hypertrophy, oxidative stress, and tubular inflammation (Figure 1). ${ }^{17}$ Some biomarkers are linked to these pathways. For instance, the renin-angiotensin-aldosterone system is associated with inflammatory cytokines such as tumor necrosis factor $\alpha$ (TNF- $\alpha$ ) and interleukin (IL) $1 \beta,{ }^{20}$ while substantial evidence suggests that angiotensin $\mathrm{II}^{21-26}$ and aldosterone ${ }^{27-29}$ are major mediators in the pathogenesis of DN. Furthermore, the role of protein kinase $\mathrm{C}(\mathrm{PKC})$ in the induction and progression of $\mathrm{DN}$ through a complex mechanism involving its isoforms (PKC- $\alpha$, PKC- $\beta$, and PKC- $\varepsilon$ ) has been well reported. ${ }^{30-33}$ These isoforms have been implicated as mediators of renal fibrosis and mesangial expansion through upregulation of vascular endothelial growth factor (VEGF) expression in
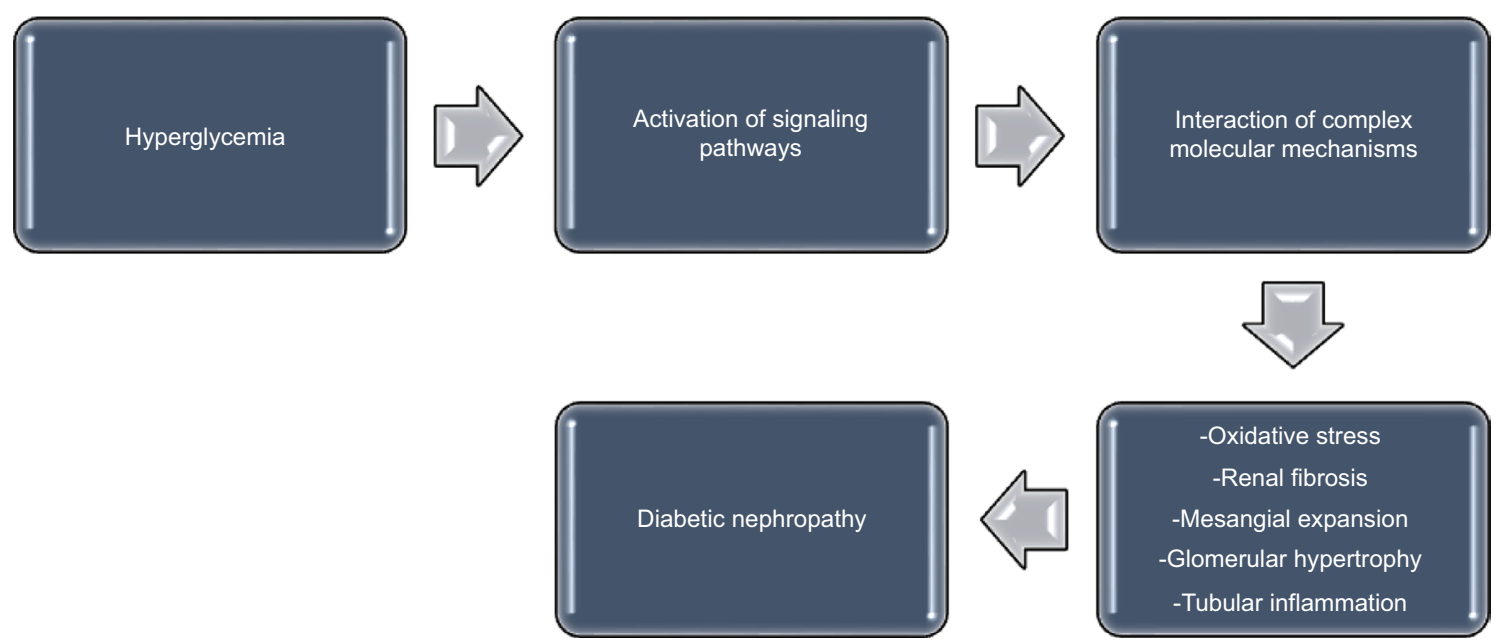

Figure I A schematic representation of the pathogenesis of diabetic nephropathy. 
mesangial cells, as well as transforming growth factor- $\beta$ (TGF- $\beta$ ), type IV collagen, laminin, and fibronectin in the glomeruli. Even as hyperglycemia-induced expression of some NADPH oxidase subunits in mesangial cells occurs in a PKC-dependent fashion, ${ }^{34,35} \mathrm{NADPH}$ oxidase-driven renal oxidative stress stimulates mesangial expansion and albuminuria by increasing the expression of fibronectin and collagen- 1 in the kidney, TGF- $\beta 1$ being the main "fibrogenic" cytokine in vivo. ${ }^{36,37}$

Finally, inflammatory cytokines such as TNF- $\alpha$, IL-1, IL-6, and IL-18 are all involved in the development and progression of $\mathrm{DN}$, as inflammation also plays a crucial role in the process. ${ }^{38}$ Remarkably, elevated levels of circulating TNF receptors in patients with T2DM have been linked with progression to ESKD,${ }^{39}$ while urinary TNF- $\alpha$ excretion has been associated with severity of glomerular and tubulointerstitial injury in patients with T2DM. ${ }^{40}$

\section{Albuminuria as the conventional biomarker}

Ideally, a little quantity of albumin is filtered in the glomerulus, and is accompanied by its near-complete reabsorption in the tubules. ${ }^{41}$ Thus, increased UAE is accepted as a well-established biomarker of glomerulopathy, ${ }^{16}$ as well as tubulopathy because in the latter, there is reduced reabsorption of the filtered albumin. ${ }^{42}$

Since albuminuria is an important component of DN, it is important to establish the definition of the different degrees of UAE. Normoalbuminuria refers to UAE of $<30 \mathrm{mg} /$ day or $20 \mu \mathrm{g} / \mathrm{min}$, while microalbuminuria and macroalbuminuria refer to UAE of $30-300 \mathrm{mg} /$ day or $20-200 \mu \mathrm{g} / \mathrm{min}$, and $>300$ $\mathrm{mg} /$ day or $200 \mu \mathrm{g} / \mathrm{min}$, respectively. ${ }^{43}$

Because baseline albuminuria is the strongest predictor of ESKD and cardiovascular morbidity in T2DM, ${ }^{44,45}$ the American Diabetes Association has recommended screening with yearly UAE in all patients with T2DM, commencing at the time of diagnosis. ${ }^{46}$

Remarkably, microalbuminuria constitutes a risk factor for chronic kidney disease and ESKD, and also serves as a powerful predictor of cardiovascular morbidity and mortality in diabetic subjects. ${ }^{47-49}$ Nevertheless, about $30 \%$ of diabetics with renal dysfunction have normoalbuminuria, ${ }^{15}$ while the cardiovascular and renal morbidity is increased in the "high normal" range of UAE. ${ }^{49-52}$

With these observations and the previously mentioned drawbacks, the use of albuminuria as the conventional biomarker for early detection of $\mathrm{DN}$ is thus becoming untenable. Moreover, recent evidence indicates that a remarkable number of patients with macroalbuminuria can revert to normoalbuminuria, while the concept of non-albuminuric $\mathrm{DN}$ is well documented, reflecting the fact that patients with diabetes mellitus can present with a reduction in GFR without progressing from normo- to macroalbuminuria. ${ }^{53} \mathrm{As}$ a result, other biomarkers (reflective of glomerular or tubular injury) are now considered as more reliable, alternative predictors of DN risk. Since tubular lesions occur early in DN, markers of tubular injury will particularly be more useful than albuminuria in the early prediction of disease.

Recently, haptoglobin has been identified as another alternative dependable biomarker. By including the haptoglobin/ creatinine ratio to a model using the albumin/creatinine ratio to predict early decline in renal function, some investigators reported an improvement in its predictive performance..$^{54}$ Thus, it was concluded that the haptoglobin/creatinine ratio may be useful to predict patients with T2DM at risk of nephropathy prior to the onset of macroalbuminuria or reduced GFR.

\section{Novel biomarkers in DN}

Biomarkers of glomerular injury, tubular injury, inflammation, and oxidative stress precede albuminuria in some patients and thus may be useful for the early prediction of $\mathrm{DN}$, although most of them still require validation. ${ }^{55,56}$ Because of the diversity of these novel biomarkers, different methods of classification have been documented for clarity. ${ }^{56}$

Some authors have classified the biomarkers according to both their origin and the already-identified pathologic processes impairing the nephron such as kidney injury, oxidative stress, and inflammation: biomarkers of renal dysfunction, inflammatory biomarkers (cytokines and chemokines), and oxidative stress biomarkers. ${ }^{16}$ Others had proposed a classification which grouped the biomarkers into three categories: glomerular, tubular, and other proteins. ${ }^{57}$

For the purpose of this review, a combination of these classifications will be used to discuss these markers (Table 1). It is equally important to note that an overlap exists in the categorization; some biomarkers of inflammation can also be regarded as glomerular markers, while some others that are grouped as miscellaneous biomarkers can also be seen as tubular or glomerular markers.

\section{Glomerular biomarkers}

These biomarkers include transferrin, immunoglobulin G (IgG), ceruloplasmin, type IV collagen, laminin, glycosaminoglycans (GAGs), lipocalin-type prostaglandin D synthase (L-PGDS), fibronectin, podocytes-podocalyxin, and VEGF. ${ }^{56}$ 
Table I Classification of the novel biomarkers

\begin{tabular}{|c|c|c|c|c|}
\hline $\begin{array}{l}\text { Glomerular } \\
\text { biomarkers }\end{array}$ & $\begin{array}{l}\text { Tubular } \\
\text { biomarkers }\end{array}$ & $\begin{array}{l}\text { Biomarkers of } \\
\text { oxidative stress }\end{array}$ & $\begin{array}{l}\text { Biomarkers of } \\
\text { inflammation }\end{array}$ & $\begin{array}{l}\text { Miscellaneous } \\
\text { biomarkers }\end{array}$ \\
\hline Transferrin & NGAL & $80 \mathrm{HdG}$ & TNF- $\alpha^{\ddagger}$ & VEGF ${ }^{\ddagger}$ \\
\hline Albumin & KIM-I & & $\mathrm{IL}-\mathrm{I} \beta^{\ddagger}$ & Podocalyxin ${ }^{\ddagger}$ \\
\hline $\lg G$ & NAG & & IL-8 $8^{\ddagger}$ & Nephrin $\neq$ \\
\hline Ceruloplasmin & Cystatin C & & $\mathrm{IL}-18^{\ddagger}$ & $\mathrm{H}-\mathrm{FABP} \#$ \\
\hline Type IV collagen & L-FABP & & $\mathrm{IP}-10^{\ddagger}$ & Retinol-binding protein ${ }^{\#}$ \\
\hline Laminin & $\alpha$-I-microglobulin & & MCP-I ${ }^{\ddagger}$ & AGEs \\
\hline GAGs & & & G-CSF ${ }^{\ddagger}$ & \\
\hline Fibronectin & & & Eotaxin $\ddagger$ & \\
\hline \multirow[t]{2}{*}{ L-PGDS } & & & Orosomucoid & \\
\hline & & & RANTES $\ddagger$ & \\
\hline
\end{tabular}

Notes: ${ }^{\ddagger}$ Also regarded as glomerular biomarkers. ${ }^{\#}$ Also regarded as tubular biomarkers.

Abbreviations: IgG, immunoglobulin G; GAGs, glycosaminoglycans; L-PGDS, lipocalin-type prostaglandin D synthase; NGAL, neutrophil gelatinase-associated lipocalin; KIM-I, kidney injury molecule I; NAG, N-acetyl- $\beta$-D-glucosaminidase; L-FABP, liver-type fatty acid-binding protein; 8oHdG, 8-oxo-7,8-dihydro-2-deoxyguanosine; TNF- $\alpha$, tumor necrosis factor $\alpha$; IL, interleukin; IP-I0, interferon gamma-induced protein; MCP-I, monocyte chemoattractant protein I; G-CSF, granulocyte colony-stimulating factor; RANTES, regulated on activation, normal T cell expressed and secreted; VEGF, vascular endothelial growth factor; H-FABP, heart fatty acid-binding protein; AGEs, advanced glycation end products.

Table 2 Summary of some of the novel biomarkers for diabetic nephropathy

\begin{tabular}{llllll}
\hline Biomarker & Type of renal injury & TIDM & T2DM & Pre-microalbuminuria ${ }^{@}$ & Predicts microalbuminuria $^{\text {TID }}$ \\
\hline Urinary transferrin & Glomerular injury & + & + & + & + \\
Urinary TNF- $\alpha$ & Glomerular injury & + & + & + & + \\
Urinary type IV collagen & Glomerular/tubular injury & + & + & + & + \\
Urinary fibronectin & Glomerular injury & + & + & & \\
Urinary GAGs & Glomerular injury & + & + & + & + \\
Urinary NAG & Tubular injury & + & + & + & + \\
Urinary L-PGDS & Glomerular injury & & + & + & + \\
\hline
\end{tabular}

Note: @Appears in urine before microalbuminuria.

Abbreviations: TIDM, type I diabetes mellitus; T2DM, type 2 diabetes mellitus; TNF- $\alpha$, tumor necrosis factor $\alpha$; GAGs, glycosaminoglycans; NAG, N-acetyl- $\beta$-Dglucosaminidase; L-PGDS, lipocalin-type prostaglandin D synthase.

Podocalyxin and VEGF are essentially considered as podocyte biomarkers.

Interestingly, newer approaches which can be used to identify potential novel biomarkers of DN have also been described; these include urinary microRNAs which are short noncoding mRNAs that regulate gene expression and urine proteomics, highlighting a possible role for epigenetic factors in the development of the disease. ${ }^{58}$ For instance, in a review to assess the correlation between changes in various mRNAs and progression of DN, some authors noted that mRNA-377, mRNA-192, mRNA-216/217, and mRNA-144 were elevated in body fluids of patients with DN, while mRNA-21 and mRNA-375 were decreased. They therefore suggested the plausibility of using urine-specific mRNAs as novel biomarkers for the diagnosis of early stages of DN. ${ }^{59}$ For glomerular biomarkers, urinary transferrin has been demonstrated as a more reliable marker of glomerular injury than albuminuria (Table 2). As a major serum ironbinding protein, transferrin conveys iron in its ferric forms to proliferative cells. ${ }^{16}$ Some reports indicate that prior to the development of microalbuminuria, urinary transferrin excretion appeared higher in diabetic subjects than in their healthy controls. ${ }^{60-62}$ In fact, urinary transferrin has been considered as a more sensitive biomarker of glomerular injury in diabetes mellitus. ${ }^{63-65}$ This is because patients with diabetes mellitus have increased likelihood of presenting with urinary transferrinuria than with albuminuria, while albumin/transferrin ratio is significantly lower in diabetic patients with normoalbuminuria and microalbuminuria than in those with macroalbuminuria ${ }^{66}$ In addition, transferrinuria predicts the development of microalbuminuria in patients with T2DM who have normoalbuminuria. ${ }^{67,68}$ Moreover, in macroalbuminuric diabetic patients, urinary transferrin excretion is positively correlated with UAE. ${ }^{69-71}$ However, transferrinuria also occurs in primary glomerulonephritis, as well as systemic diseases which secondarily affect the glomerulus, thus underscoring its lack of specificity to DN. ${ }^{72}$

Urinary IgG is another related biomarker. The immunoglobulin is an anionic plasma protein which crosses the glomerulus with difficulty, but appears in the urine concomitantly with elevated values of urinary transferrin, urinary ceruloplasmin, and urinary orosomucoid before the onset of 
microalbuminuria, which suggests the ability of increased elimination of urinary $\operatorname{IgG}$ to predict microalbuminuria in DM patients. ${ }^{73}$ For urinary ceruloplasmin, this coppertransporting serum protein is filtered with difficulty through the glomerular barrier because it is negatively charged like IgG. ${ }^{74}$ Similar to urinary transferrin and urinary IgG, urinary ceruloplasmin can predict DN earlier than albuminuria in T2DM patients; in fact, the values of the three markers can be elevated concomitantly. ${ }^{75}$ Both laminin and type IV collagen are components of glomerular basement membrane, although the latter is also a component of mesangial matrix. Since elevated urinary levels of type IV collagen occur in normoalbuminuric patients with T1DM, the biomarker can also be used as an early predictor of $\mathrm{DN},{ }^{75}$ and has actually been considered to be a specific indicator of early DN. ${ }^{76}$

Moreover, some studies indicate that urinary excretion of type IV collagen in T2DM is related to UAE, ${ }^{77-79}$ while other investigators have shown that T2DM patients with evidence of kidney disease present with a significantly higher type IV collagen/albumin ratio compared to their nondiabetic counterparts with nephropathy. ${ }^{77,78}$ Again, these findings support the possible use of urinary type IV collagen in the differentiation of DN from nondiabetic nephropathy. Finally, urinary type IV collagen has also been found to show more sensitivity than albuminuria in the detection of renal injury in patients with $\mathrm{T} 2 \mathrm{DM},{ }^{75}$ although other authors have reported that as many as one third of patients with microalbuminuria do not have increased urinary type IV collagen excretion. ${ }^{80}$ Remarkably, several studies have shown that urinary laminin excretion is higher in patients with diabetes mellitus in comparison to their healthy controls, even prior to the onset of microalbuminuria. ${ }^{78,81,82}$ To buttress the discriminatory role of this biomarker in diabetic and nondiabetic kidney disease, it has been reported that patients with T2DM who show evidence of nephropathy present with significantly higher laminin/albumin ratio compared to patients with nondiabetic nephropathy. ${ }^{78}$

Urinary fibronectin is probably another useful biomarker of DN, but its relevance compared to albuminuria needs to be validated by further studies. Nevertheless, as an intrinsic component of the glomerular extracellular matrix, the urinary excretion of this high-molecular-weight protein is noted to be higher in subjects with diabetes mellitus compared to their controls, with a significant difference observed only in patients with macroalbuminuria ${ }^{83,84}$ Further evidences pointing to its possible predictive role in DN include its higher excretion in diabetic subjects with microalbuminuria than in those with normoalbuminuria, ${ }^{83}$ the correlation of its urinary levels with the progression of biopsy-proven glomerular diffuse lesions, ${ }^{85}$ and the correlation of its degradation products with UAE. ${ }^{86}$

Urinary GAGs are increased in DM patients with normoalbuminuria, ${ }^{87}$ and are associated with other tubular markers such as Tamm-Horsfall protein, which expresses a distal tubular dysfunction in patients with diabetes mellitus. ${ }^{88}$ GAGs are also present at the level of the tubular basement membrane. Finally, L-PGDS is a biomarker related to lesions of the glomerular capillary walls and reflects their increased permeability. Although it is basically considered to predict renal lesions, it is less relevant as an early biomarker of $\mathrm{DN} .{ }^{89}$

\section{Tubular biomarkers}

Notably, tubulointerstitial lesions are also associated with glomerular injury during DN. ${ }^{90}$ Interestingly, tubular biomarkers have shown that tubular dysfunction can be present early in DN, occasionally preceding glomerular injury. This observation underscores the fact that tubular biomarkers are early predictors of DN compared to microalbuminuria and other glomerular biomarkers. Examples of tubular biomarkers include neutrophil gelatinase-associated lipocalin (NGAL), $\alpha-1$-microglobulin, kidney injury molecule 1 (KIM-1), N-acetyl- $\beta$-D-glucosaminidase (NAG), cystatin C, and liver-type fatty acid-binding protein (L-FABP).

A recent review of diagnostic markers which can detect $\mathrm{DN}$ at an early stage shows that urinary tubular markers like NAG, $\alpha-1$-microglobulin, L-FABP, as well as other makers such as nephrin and angiotensinogen may be elevated before the appearance of microalbuminuria in T2DM. ${ }^{91}$

Similarly, elevated urinary NGAL is present in normoalbuminuric diabetic patients, as well as used to assess tubular lesions in the disease, ${ }^{92}$ and has been shown to precede microalbuminuria in T1DM. ${ }^{93,94}$ In addition, high values of this biomarker were noted in T2DM patients with normoalbuminuria which rose progressively in patients with microalbuminuria and macroalbuminuria. ${ }^{95}$ Thus, urinary NGAL in T2DM patients likely has a role in predicting the evolution of disease. ${ }^{96}$

Regarding $\alpha$-1-microglobulin, it is normally filtered through the glomerulus and reabsorbed in the proximal tubule; tubular dysfunction thus impairs its reabsorption resulting in its urinary excretion. A study has shown that normoalbuminuric T2DM patients had elevated urinary levels of this biomarker, given that tubular injury precedes the onset of microalbuminuria, making it a more sensitive and an earlier urinary biomarker. ${ }^{97}$ Besides, urinary $\alpha-1$-microglobulin in early stages of diabetes mellitus could also have a role in 
predicting $\mathrm{DN},{ }^{98}$ and has been identified as an inexpensive biomarker for the early diagnosis of DN. ${ }^{99}$

There appears to be disparate findings about the sensitivity of NAG as a biomarker for the early prediction of DN. While some authors reported that NAG can be considered an early tubular biomarker as well as the most sensitive biomarker for detecting early renal injury in diabetic patients, ${ }^{100,101}$ others failed to demonstrate any clinical significance as an early biomarker of DN. ${ }^{102}$ Nevertheless, as a sensitive tubular biomarker, increased urinary NAG can precede the appearance of microalbuminuria in T1DM. ${ }^{103}$

For cystatin $\mathrm{C}$, its urinary excretion suggests tubular injury as it is elevated early in diabetes and prediabetic nephropathy, together with NGAL. ${ }^{104}$ Besides the predictive role of urinary cystatin $\mathrm{C}$ for the progression of $\mathrm{DN},{ }^{105}$ its serum and urinary levels are useful biomarkers for assessing early nephropathy in T2DM. ${ }^{106}$

Although KIM-1, as tubular transmembrane glycoprotein, is a well-known sensitive biomarker for acute kidney injury, ${ }^{107}$ increased urinary levels have been reported in normoalbuminuric T2DM patients, indicating lesions of the proximal tubule in early stages of the disease. Moreover, microalbuminuric patients have higher urinary KIM-1 levels than those with normoalbuminuria. ${ }^{108}$ Another tubular biomarker with good predictive ability for diabetic kidney disease is urinary L-FABP. Elevated levels of this biomarker were found in normoalbuminuric T1DM patients; urinary L-FABP has a predictive role with respect to the evolution toward microalbuminuria, and of microalbuminuria toward macroalbuminuria. ${ }^{109}$ Similarly, patients with normoalbuminuric T2DM also presented high levels of urinary L-FABP, this protein being considered as a useful biomarker for diagnosing early $\mathrm{DN},{ }^{110}$ as well as an independent predictor of the progression of DN. ${ }^{111}$

\section{Biomarkers of inflammation}

Biomarkers of inflammation such as TNF- $\alpha$ and IL- $1 \beta$, which are cytokines involved in the onset and progression of DN, also play predictive roles in the DN. ${ }^{112,113}$ A study by a group of researchers was the first to suggest that these proinflammatory cytokines could participate in the development of DN. ${ }^{114}$ In this study, macrophages incubated with glomerular basement membranes from diabetic rats produced significantly greater levels of IL- $1 \beta$ and TNF- $\alpha$ than macrophages incubated with membranes of normal nondiabetic rats. ${ }^{114}$ However, scientific attention has been directed more at the implications of TNF- $\alpha$ in the context of DN. TNF- $\alpha$ is reported to exert cytotoxic effect on glomerular, mesangial, and epithelial cells, and may trigger direct renal injury. ${ }^{15,116}$ In addition, increased urinary TNF- $\alpha$ excretion and elevated TNF- $\alpha$ levels in renal interstitial fluid have been observed to precede a significantly increased albuminuria in experimental murine models. ${ }^{117}$ Similarly, the findings from clinical studies indicate a direct and significant relationship between urinary protein excretion and serum TNF- $\alpha$ in diabetic patients with normal renal function and microalbuminuria on one hand, as well as in patients with overt nephropathy and ESKD on the other hand. ${ }^{118,119}$ Notably, the fact that urinary TNF- $\alpha$ levels are elevated in diabetic patients who have increased UAE, coupled with the significant rise of urinary TNF- $\alpha$ excretion as DN progresses, strongly supports the prospect of using this cytokine as a biomarker for predicting DN. ${ }^{113}$

Other biomarkers of inflammation, which are also glomerular markers, include IL-18, interferon gammainduced protein (IP-10), monocyte chemoattractant protein 1 (MCP-1), granulocyte colony-stimulating factor (G-CSF), eotaxins, RANTES (regulated on activation, normal $\mathrm{T}$ cell expressed and secreted) or CCL-5, and orosomucoid. IL-18 is a proinflammatory cytokine originating from mononuclear cells. Its serum and urinary levels have been reported to correlate positively with albumin excretion rate, while its serum levels also correlate positively with carotid intimamedia thickness in patients with T2DM, and thus may be a predictor of DN progression, as well as cardiovascular diseases. ${ }^{120,121}$ IP-10 and MCP-1 are other proinflammatory cytokines whose serum levels are significantly increased in subjects with T2DM. ${ }^{121}$ Moreover, serum and urinary levels of these two proinflammatory cytokines were found to be positively correlated with albumin excretion rate and intimamedia thickness, suggesting that microinflammation may be a common risk factor for $\mathrm{DN}$ and atherosclerosis in T2DM. ${ }^{121}$ Serum and urinary G-CSF levels are also increased in the early stages of DN, ${ }^{122}$ while urinary RANTES (or CCL-5) and eotaxin excretion rates were noted to be significantly higher in hyperfiltering than in normofiltering T1DM patients. ${ }^{123}$ Like RANTES which is a chemotactic cytokine, eotaxins are a chemotactic cytokine subfamily of eosinophil chemotactic proteins consisting of eotaxin-1 (CCL-11), eotaxin-2 (CCL-24), and eotaxin-3 (CCL-26). ${ }^{124}$ The high urinary levels of eotaxin and RANTES, from hyperfiltration in the diabetic kidney, occur as result of high intraglomerular pressure which causes renal inflammation, inflammation being a component of DN. ${ }^{123}$

Finally, some investigators reported high IL-8 and MCP-1 levels in early and late stages of DN in T2DM patients, respectively, ${ }^{125}$ while another study on T2DM patients with 
normoalbuminuria and microalbuminuria reported higher values of IL-8, IP10, MCP-1, G-CSF, eotaxin, and RANTES in patients with microalbuminuria than in those with normoalbuminuria. ${ }^{126}$ Urinary orosomucoid has been noted to be high in T1DM patients with normoalbuminuria than in controls, while the levels increase in patients with microalbuminuria and macroalbuminuria. ${ }^{127}$ In addition, T2DM patients were reported to present with increased urinary orosomucoid, in parallel with the excretion of $\mathrm{IgG}$, ceruloplasmin, and transferrin. ${ }^{128}$

\section{Biomarkers of oxidative stress}

A typical example of a biomarker of oxidative stress is urinary 8-oxo-7,8-dihydro-2-deoxyguanosine (8oHdG). This marker is produced secondary to oxidative DNA damage, and appears in the urine without being metabolized. ${ }^{129}$ Remarkably, urinary $80 \mathrm{HdG}$ has been reported as a useful clinical marker to predict the development of $\mathrm{DN}$ in diabetic patients given the observation of a significant progression of $\mathrm{DN}$ in the patients with higher excretion of the biomarker in urine compared with their counterparts with moderate or lower excretion of the molecule. ${ }^{130}$

\section{Miscellaneous biomarkers}

These include some tubular markers such as urinary heart fatty acid-binding protein and urinary retinol-binding protein, podocyte biomarkers such as podocalyxin, nephrin, and VEGF, as well as urinary proteomics and urinary advanced glycation end products (AGEs). These podocyte biomarkers are also regarded as glomerular markers. Nephrin is a slit diaphragm protein whose expression is reduced in late proteinuric phase of experimental DN, suggesting that reduced nephrin expression may be a determinant of glomerular hyperpermeability in DN. ${ }^{131,132}$ Since podocyte dysfunction occurs in diabetes mellitus and $\mathrm{DN}$ is actually considered a podocytopathy, nephrinuria has been reported in some T1DM patients before the onset of microalbuminuria, ${ }^{133}$ as well as in some normoalbuminuric T2DM patients. ${ }^{134}$ Furthermore, another podocyte biomarker like urinary VEGF has been found to be increased in T2DM patients with microalbuminuria and macroalbuminuria, ${ }^{135}$ while higher levels of podocalyxin were seen in diabetic patients with microalbuminuria than in diabetic patients with normoalbuminuria. ${ }^{136}$ Finally, some authors have reported that high values of urinary AGEs were seen in $50 \%$ of the T2DM patients with normoalbuminuria and in $85 \%$ of those with microalbuminuria. ${ }^{137}$

\section{Conclusion}

Albuminuria is the conventional biomarker for the detection and prediction of DN and cardiovascular risk in T1DM and T2DM, although it has several limitations. Thus, there is now a focus on novel biomarkers which have higher sensitivity and specificity for earlier detection of $\mathrm{DN}$, as well as for a more precise prediction of its progression to ESKD.

Although these biomarkers are potentially useful for the evaluation of diabetic kidney disease, current data still preclude the routine clinical use of majority of them. Nevertheless, the research trajectory on novel biomarkers for DN should take the course of persistent efforts at their discovery, their validation using high-quality and large longitudinal studies, and subsequent development of a biomarker panel which can reliably predict and evaluate this renal microvascular disease.

\section{Acknowledgments}

The author acknowledges the invaluable information obtained from the studies by Arora and Singh, ${ }^{17}$ Cohen-Bucay andViswanathan, ${ }^{43}$ and Gluhovschi et $\mathrm{al}^{56}$ during the preparation of the manuscript.

\section{Disclosure}

The author reports no conflicts of interest in this work.

\section{References}

1. Koulouridis E. Diabetic nephropathy in children and adolescents and its consequences in adults. J Pediatr Endocrinol Metab. 2001;14 (Suppl 5):S1367-S1377.

2. Uwaezuoke SN. Prevention of diabetic nephropathy in children and adolescents: how effective are the current strategies? Int J Diabetol Vasc Dis Res. 2015;:S5:001:1-5.

3. Deferrari G, Repetto M, Calvi C, Ciabattoni M, Rossi C, Robaudo C. Diabetic nephropathy: from micro- to microalbuminuria. Nephrol Dial Transplant. 1998;13 (Suppl 8):S11-S15.

4. Danne T, Kordonouri O, Hövener G, Weber B. Diabetic angiopathy in children. Diabet Med. 1997;14(12):1012-1025.

5. Maghribi H, Abu-Odeh A. Early diabetic nephropathy in a pediatric patient. JRMS. 2006;13(1):51-53.

6. Francis J, Rose SJ, Raafat F, Milford DV. Early onset of diabetic nephropathy. Arch Dis Child. 1997;77(6):524-525.

7. DeClue TJ, Campos A. Diabetic nephropathy in a prepubertal diabetic female. J Pediatr Endocrinol. 1994;7(1):43-46.

8. Remuzzi G, Schieppati A, Ruggenenti P. Nephropathy in patients with type 2 diabetes. $N$ Engl J Med. 2002;346(15):1145-1151.

9. American Diabetes Association. Position statement: diabetic nephropathy. Diabetes Care. 1999;22 (Suppl 1):S66-S69.

10. Caramori ML, Fioretto P, Mauer M. The need for early predictors of diabetic nephropathy risk: is albumin excretion rate sufficient? Diabetes. 2000;49(9):1399-1408.

11. Perkins BA, Ficociello LH, Silva KH, Finkelstein DM, Warram JH, Krolewski AS. Regression of microalbuminuria in type 1 diabetes. N Engl J Med. 2003;348(23):2285-2293. 
12. Giorgino F, Laviola L, Cavallo Perin P, Solnica B, Fuller J, Chaturvedi N. Factors associated with progression to macroalbuminuria in microalbuminuric type 1 diabetic patients: the EURODIAB Prospective Complications Study. Diabetologia. 2004;47(6):1020-1028.

13. Caramori ML, Fioretto P, Mauer M. Enhancing the predictive value of urinary albumin for diabetic nephropathy. JAm Soc Nephrol. 2006;17(2): 339-352.

14. Adler AI, Stevens RJ, Manley SE, Bilous RW, Cull CA, Holman RR; UKPDS GROUP. Development and progression of nephropathy in type 2 diabetes: the United Kingdom prospective diabetes study (UKPDS 64). Kidney Int. 2003;63(1):225-232.

15. An JH, Cho YM, Yu HG, et al. The clinical characteristics of normoalbuminuric renal insufficiency in Korean type 2 diabetic patients: a possible early stage renal complication. J Korean Med Sci. 2009;24 Suppl:S75-S81.

16. Matheson A, Willcox MDP, Flanagan J, Walsh BJ. Urinary biomarkers involved in type 2 diabetes: a review. Diabetes Metab Res Rev. 2010;26(3):150-171

17. Arora MK, Singh UK. Molecular mechanisms in the pathogenesis of diabetic nephropathy: an update. Vascul Pharmacol. 2013;58(4): 259-271.

18. Wada J, Makino H. Inflammation and the pathogenesis of diabetic nephropathy. Clin Sci (Lond). 2013;124(3):139-152.

19. Tavridou A, Georgoulidou A, Roumeliotis A, et al. Association of plasma adiponectin and oxidized low-density lipoprotein with carotid intima-media thickness in diabetic nephropathy. J Diabetes Res. 2015;2015:507265.

20. Matavelli LC, Huang J, Siragy HM. (Pro)renin receptor contributes to diabetic nephropathy by enhancing renal inflammatory. Clin Exp Pharmacol Physiol. 2010;37(3):277-282.

21. Egido J. Vasoactive hormones and renal sclerosis. Kidney Int. 1996;49(2):578-597.

22. Feliers D, Gorin Y, Ghosh-Choudhury G, Abbound HE, Kasinath BS. Angiotensin II stimulation of VEGF mRNA translation requires production of reactive oxygen species. Am J Physiol Renal Physiol. 2006;290(4):927-936.

23. Nakamura S, Nakamura I, Ma L, Vaughan DE, Fogo AB. Plasminogen activator inhibitor-1 (PAI-1) expression is regulated by the angiotensin type 1 receptor in vivo. Kidney Int. 2000;58(1):251-259.

24. Ruiz-Ortega M, Rupérez M, Esteban V, et al. Angiotensin II: a key factor in the inflammatory and fibrotic response in kidney diseases. Nephrol Dial Transplant. 2006;21(1):16-20.

25. Kang YS, Park YG, Kim BK, et al. Angiotensin II stimulates the synthesis of vascular endothelial growth factor through the p38 mitogen activated protein kinase pathway in cultured mouse podocytes. $J \mathrm{Mol}$ Endocrinol. 2006;36(2):377-388.

26. Giacchetti G, Sechi LA, Rilli S, Carey RM. The renin-angiotensinaldosterone system, glucose metabolism and diabetes. Trends Endocrinol Metabol. 2005;16(3):120-126.

27. Fujisawa G, Okada K, Muto S, et al. Spironolactone prevents early renal injury in streptozotocin-induced diabetic rats. Kidney Int. 2004;66(4):1493-1502.

28. Taira M, Toba H, Murakami M, et al. Spironolactone exhibits direct renoprotective effects and inhibits renin-angiotensin-aldosterone system in diabetic rats. Eur J Pharmacol. 2008;589(1-3):264-271.

29. Guo C, Martinez-Vasquez D, Mendez GP, et al. Mineralocorticoid receptor antagonist reduces renal injury in rodent models of types 1 and 2 diabetes mellitus. Endocrinology. 2006;147(11):5363-5373.

30. Thallas-Bonke V, Thorpe SR, Coughlan MT, et al. Inhibition of NADPH oxidase prevents advanced glycation end product-mediated damage in diabetic nephropathy through a protein kinase C-alphadependent pathway. Diabetes. 2008;57(2):460-469.

31. Yao L, Wang J, Mao Y, Zhu H, Deng A, Zhu Z. Different expressions of protein kinase C-alpha, beta I and beta II in glomeruli of diabetic nephropathy patients. J Huazhong Univ Sci Technology Med Sci. 2006;26(6): 651-653.
32. Xia L, Wang H, Munk S, et al. Reactive oxygen species, PKC-beta I and PKC-zeta mediate high glucose-induced vascular endothelial growth factor expression in mesangial cells. Am J Physiol Endocrinol Metab. 2007;293(5):E1280-E1288.

33. Koya D, Jirousek MR, Lin YW, Ishii H, Kuboki K, King GI. Characterization of protein kinase $\mathrm{C}$ beta isoform activation on the gene expression of transforming growth factor- $\beta$, extracellular matrix components and prostanoids in the glomeruli of diabetic rats. $J$ Clin Invest. 1997;100(1):115-126.

34. Gorin Y, Block K, Hernandez J, et al. Nox4 NAD(P)H oxidase mediates hypertrophy and fibronectin expression in the diabetic kidney. J Biol Chem. 2005;280(47):39616-39626.

35. Xia L, Wang H, Goldberg HJ, Munk S, Fantus IG, Whiteside CI. Mesangial cell NADPH oxidase upregulation in high glucose is protein kinase $\mathrm{C}$ dependent and required for collagen IV expression. Am J Physiol Renal Physiol. 2006;290(2):F345-F356.

36. Asaba K, Tojo A, Onozato ML, et al. Effects of NADPH oxidase inhibitor in diabetic nephropathy. Kidney Int. 2005;67(5):1890-1898.

37. Zugmaier G, Paik S, Wilding G, et al. Transforming growth factor beta 1 induces cachexia and systemic fibrosis without an antitumor effect in nude mice. Cancer Res. 1991;51(13):3590-3594.

38. Moriwaki Y, Yamamoto T, Shbutani Y, et al. Elevated levels of interleukin-18 and tumor necrosis factor-alpha in serum of patients with type 2 diabetes mellitus: relationship with diabetic nephropathy. Metabolism. 2003;52(5):605-608.

39. Niewczas MA, Gohda T, Skupien J, et al. Circulating TNF receptors 1 and 2 predict ESRD in type 2 diabetes. JAm Soc Nephrol. 2012;23(3):507-515.

40. Navarro JF, Mora C, Muros M, Garcia J. Urinary tumour necrosis-alpha excretion independently correlates with clinical markers of glomerular and tubulo-interstitial injury in type 2 diabetic patients. Nephrol Dial Transplant. 2006;21(12):3428-3434.

41. Haraldsson B, Nyström J, Deen WM. Properties of the glomerular barrier and mechanisms of proteinuria. Physiol Rev. 2008;88(2):451-487.

42. Birn H, Christensen EI. Renal albumin absorption in physiology and pathology. Kidney Int. 2006;69(3):440-449.

43. Cohen-Bucay A, Viswanathan G. Urinary markers of glomerular injury in diabetic nephropathy. Int J Nephrol. 2012;2012:146987.

44. de Zeeuw D, Ramjit D, Zhang Z, et al. Renal risk and renoprotection among ethnic groups with type 2 diabetic nephropathy: a post hoc analysis of RENAAL. Kidney Int. 2006;69(9):1675-1682.

45. de Zeeuw D, Remuzzi G, Parving HH, et al. Albuminuria, a therapeutic target for cardiovascular protection in type 2 diabetic patients with nephropathy. Circulation. 2004;110(8):921-927.

46. American Diabetes Association. Standards of medical care in diabetes2014. Diabetes Care. 2014;37 (Suppl 1):S14-S80.

47. Ninomiya T, Perkovic V, de Galan BE, et al; ADVANCE Collaborative Group. Albuminuria and kidney function independently predict cardiovascular and renal outcomes in diabetes. J Am Soc Nephrol. 2009;20(8):1813-1821.

48. Dinneen SF, Gerstein HC. The association of microalbuminuria and mortality in none-insulin-dependent diabetes mellitus: a systematic overview of the literature. Arch Int Med. 1997;157(13):1413-1418.

49. Ruggenenti P, Remuzzi G. Time to abandon microalbuminuria? Kidney Int. 2006;70(7):1214-1222.

50. Gerstein HC, Mann JF, Yi Q, et al; HOPE Study Investigators. Albuminuria and risk of cardiovascular events, death, and heart failure in diabetic and nondiabetic individuals. JAMA. 2001;286(4):421-426.

51. Klausen K, Borch-Johnsen K, Feldt-Rasmussen B, et al. Very low levels of microalbuminuria are associated with increased risk of coronary heart disease and death independently of renal function, hypertension, and diabetes. Circulation. 2004;110(1):32-35.

52. Wachtell K, Ibsen H, Olsen MH, et al. Albuminuria and cardiovascular risk in hypertensive patients with left ventricular hypertrophy: the LIFE study. Ann Int Med. 2003;139(11):901-906.

53. Currie G, McKay G, Delles C. Biomarkers in diabetic nephropathy: present and future. World J Diabetes. 2014;5(6):763-776. 
54. Bhensdadia NM, Hunt KJ, Lopes-Virella MF, et al; Veterans Affairs Diabetes Trial (VADT) study group. Urine haptoglobin levels predict early renal functional decline in patients with type 2 diabetes. Kidney Int. 2013;83(6):1136-1143.

55. Moresco RN, Sangoi MB, De Carvalho JA, Tatsch E, Bochi GV. Diabetic nephropathy: traditional to proteomic markers. Clin Chim Acta. 2013;421: 17-30.

56. Gluhovschi C, Gluhovschi G, Petrica L, et al. Urinary biomarkers in the assessment of early diabetic nephropathy. J Diabetes Res. 2016;2016:4626125.

57. Hong CY, Chia KS. Markers of diabetic nephropathy. J Diabetes Complications. 1998;12(1):43-60.

58. Lee SY, Choi ME. Urinary biomarkers for early diabetic nephropathy: beyond albuminuria. Pediatr Nephrol. 2015;30(7):1063-1075.

59. Yang Y, Xiao L, Li J, Kanwar YS, Liu F, Sun L. Urine miRNAs: potential biomarkers for monitoring progression of early stages of diabetic nephropathy. Med Hypotheses. 2013;81(2):274-278.

60. Narita T, Hosoba M, Miura T, et al. Low dose of losartan decreased urinary excretions of $\mathrm{IgG}$, transferrin, and ceruloplasmin withou reducing albuminuria in normoalbuminuric type 2 diabetic patients. Horm Metab Res. 2008;40(4):292-295.

61. Cheung CK, Cockram CS, Yeung VT, Swaminathan R. Urinary excretion of transferrin by non-insulin-dependent diabetics: a marker for early complications? Clin Chem. 1989;35(8):1672-1674.

62. Martin P, Walton C, Chapman C, Bodansky HJ, Stickland MH. Increased urinary excretion of transferrin in children with type 1 diabetes mellitus. Diabet Med. 1990;7(1):35-40.

63. O'Donnell MJ, Martin P, Florkowski CM, et al. Urinary transferrin excretion in type 1 (insulin-dependent) diabetes mellitus. Diabet Med. 1991;8(7):657-661.

64. Bernard AM, Amor AA, Goemaere-Vanneste J, et al. Microtransferrinuria is a more sensitive indicator of early glomerular damage in diabetes than microalbuminuria. Clin Chem. 1988;34(9):1920-1921.

65. O'Donnell MJ, Martin P, Cavan D, et al. Increased urinary transferrin excretion in exercising normoalbuminuric insulin-dependent diabetic patients. Ann Clin Biochem. 1991;28(Pt 5):456-460.

66. McCormick CP, Konen JC, Shihabi ZK. Microtransferrinuria and microalbuminuria: in the diabetic human. Clin Physiol Biochem. 1989;8(2):53-58.

67. Kazumi T, Hozumi T, Ishida Y, et al. Increased urinary transferrin excretion predicts microalbuminuria in patients with type 2 diabetes. Diabetes Care. 1999;22(7):1176-1180.

68. Narita T, Hosoba M, Kakei M, Ito S. Increased urinary excretions of immunoglobulin $\mathrm{G}$, ceruloplasmin, and transferrin predict development of microalbuminuria in patients with type 2 diabetes. Diabetes Care. 2006;29(1):142-144.

69. Sasaki A, Oikawa S, Toyota T. Microalbuminuria is closely related to diabetic macroangiopathy. Diabetes Res Clin Pract. 1999;44(1):35-40.

70. Bernard A, Amor AO, Goemare-Vanneste J, et al. Urinary proteins and red blood cell membrane negative charges in diabetes mellitus. Clin Chim Acta. 1990;190(3):249-262.

71. Martin P, Tindall H, Harvey JN, Handley TM, Chapman C, Davies JA. Glomerular and tubular proteinuria in type 1 (insulin-dependent) diabetic patients with and without retinopathy. Ann Clin Biochem. 1992;29(Pt 3):265-270.

72. Yaqoob M, McClelland P, Patrick AW, Stevenson A, Mason H, Bell GM. Tubular damage in microalbuminuric patients with primary glomerulonephritis and diabetic nephropathy. Ren Fail. 1995;17(1):43-49.

73. Narita T, Sasaki H, Hosoba M, et al. Parallel increase in urinary excretion rates of immunoglobulin $\mathrm{G}$, ceruloplasmin, transferrin, and orosomucoid in normoalbuminuric type 2 diabetic patients. Diabetes Care. 2004;27(5):1176-1181.

74. Wang C, Li C, Gong W, Lou T. New urinary biomarkers for diabetic kidney disease. Biomarker Res. 2013;1:9.

75. Kotajima N, Kimura T, Kanda T, et al. Type IV collagen as an early marker for diabetic nephropathy in non-insulin-dependent diabetes mellitus. J Diabetes Complications. 2000;14(1):13-17.
76. Tan Y, Yang Y, Zhang Z, Zhang X, Liu Y. Urinary type IV collagen: a specific indicator of incipient diabetic nephropathy. Chin Med J (Engl). 2002;115(3):389-394.

77. Kado S, Aoki A, Wada S, et al. Urinary type IV collagen as a marker for early diabetic nephropathy. Diabetes Res Clin Pract. 1996;31(1-3):103-108.

78. Banu N, Hara H, Okamura M, Egusa G, Yamakido M. Urinary excretion of type IV collagen and laminin in the evaluation of nephropathy in NIDDM: comparison with urinary albumin and markers of tubular dysfunction and/or damage. Diabetes Res Clin Pract. 1995;29(1):57-67.

79. Sthaneshwar P, Chan SP. Urinary type IV collagen levels in diabetes mellitus. Malays J Pathol. 2010;32(1):43-47.

80. Iijima T, Suzuki S, Sekizuka K, et al. Follow-up study on urinary type IV collagen in patients with early stage diabetic nephropathy. J Clin Lab Anal. 1998;12(6):378-382.

81. Haiyashi Y, Makino H, Ota Z. Serum and urinary concentrations of type IV collagen and laminin as a marker of microangiopathy in diabetes. Diabet Med. 1992;9(4):366-370.

82. Miyake H, Nagashima K, Yagi H, Onigata K. Urinary laminin P1 as an index of glycemic control in children with insulin-dependent diabetes mellitus. Diabetes Res. 1992;23(3):131-138.

83. Takahashi M. Increased urinary fibronectin excretion in type II diabetic patients with microalbuminuria. Nihon Jinzo Gakkai Shi. 1995;37(6):336-342

84. Fagerudd JA, Groop PH, Honkanen E, Teppo AM, GrönhagenRiska C. Urinary excretion of TGF- $\beta 1$, PDGF-BB and fibronectin in insulin-dependent diabetes mellitus patients. Kidney Int. 1997;51(63):S195-S197.

85. Kanauchi M, Nishioka H, Hashimoto T, Dohi K. Diagnostic significance of urinary transferrin in diabetic nephropathy. Nihon Jinzo Gakkai Shi. 1995;37(11):649-654.

86. Kuboki K, Tada H, Shin K, Oshima Y, Isogai S. Relationship between urinary excretion of fibronectin degradation products and proteinuria in diabetic patients, and their suppression after continuous subcutaneous heparin infusion. Diabetes Res Clin Pract. 1993;21(1):61-66.

87. Ueta I, Takamatsu K, Hashimoto K. Urinary glycosaminoglycans in patients with incipient diabetic nephropathy. Nihon Jinzo Gakkai Shi. 1995;37(1):17-23.

88. Torffvit O. Urinary sulphated glycosaminoglycans and Tamm-Horsfall protein in type 1 diabetic patients. Scand J Urol Nephrol. 1999;33(5): 328-332.

89. Uehara Y, Makino H, Seiki K, Urade Y; L-PGDS Clinical Research Group of Kidney. Urinary excretions of lipocalin-type prostaglandin D synthase predict renal injury in type-2 diabetes: a cross-sectional and prospective multi-center study. Nephrol Dial Transplant. 2009;24(2):475-482.

90. Mise K, Hoshino J, Ueno T, et al. Prognostic value of tubulointerstitial lesions, urinary $\mathrm{N}$-acetyl- $\beta$-d-glucosaminidase, and urinary $\beta 2$-microglobulin in patients with type 2 diabetes and biopsyproven diabetic nephropathy. Clin J Am Soc Nephrol. 2016;11(4): 593-601.

91. Fiseha T. Urinary biomarkers for early diabetic nephropathy in type 2 diabetic patients. Biomark Res. 2015;3(1):16.

92. Bolignano D, Lacquaniti A, Coppolino G, et al. Neutrophil gelatinaseassociated lipocalin as an early biomarker of nephropathy in diabetic patients. Kidney Blood Press Res. 2009;32(2):91-98.

93. Yürük Yıldırım Z, Nayır A, Yılmaz A, Gedikbası A, Bundak R. Neutrophil gelatinase-associated lipocalin as an early sign of diabetic kidney injury in children. J Clin Res Pediatr Endocrinol. 2015;7(4):274-279.

94. Lacquaniti A, Donato V, Pintaudi B, et al. "Normoalbuminuric" diabetic nephropathy: tubular damage and NGAL. Acta Diabetol. 2013;50(6):935-942.

95. de Carvalho JA, Tatsch E, Hausen BS, et al. Urinary kidney injury molecule-1 and neutrophil gelatinase-associated lipocalin as indicators of tubular damage in normoalbuminuric patients with type 2 diabetes. Clin Biochem. 2016;49(3):232-236. 
96. Yang YH, He XJ, Chen SR, Wang L, Li EM, Xu LY. Changes of serum and urine neutrophil gelatinase-associated lipocalin in type-2 diabetic patients with nephropathy: one year observational follow-up study. Endocrine. 2009;36(1):45-51.

97. Hong CY, Hughes K, Chia KS, Ng V, Ling SL. Urinary alpha1microglobulin as a marker of nephropathy in type 2 diabetic Asian subjects in Singapore. Diabetes Care. 2003;26(2):338-342.

98. Wainai H, Katsukawa F, Takei I, Maruyama H, Kataoka K, Saruta T. Influence of glycemic control and hypertension on urinary microprotein excretion in non-insulin-dependent diabetes mellitus. J Diabetes Complications. 1991;5(2-3):160-161.

99. Shore N, Khurshid R, Saleem M. Alpha-1microglobulin: a marker for early detection of tubular disorders in diabetic nephropathy. $J$ Ayub Med Coll Abbottabad. 2010;22(4):53-55.

100. Patel DN, Kalia K. Efficacy of urinary N-acetyl- $\beta$-D glucosaminidase to evaluate early renal tubular damage as a consequence of type 2 diabetes mellitus: a cross-sectional study. Int J Diabetes Dev Ctries. 2015;35 Suppl 3:449-457.

101. Assal HS, Tawfeek S, Rasheld EA, El-Lebedy D, Thabet EH. Serum cystatin $\mathrm{C}$ and tubular urinary enzymes as biomarkers: a renal dysfunction in type 2 diabetes mellitus. Clin Med Insights Endocrinol Diabetes. 2013;6:7-13.

102. Ambade V, Singh P, Somani BL, Basannar D. Urinary N-acetyl $\beta$-glucosaminidase and $\gamma$-glutamyl transferase as early markers of diabetic nephropathy. Indian J Clin Biochem. 2006;21(2):142-148.

103. Jones AP, Lock S, Griffiths KD. Urinary N-acetyl- $\beta$-glucosaminidase activity in type I diabetes mellitus. Ann Clin Biochem. 1995;32(Pt 1):58-62.

104. Garg V, Kumar M, Mahapatra HS, Chitkara A, Gadpayle AK, Sekhar V. Novel urinary biomarkers in pre-diabetic nephropathy. Clin Exp Nephrol. 2015;19(5):895-900.

105. Kim SS, Song SH, Kim IJ, et al. Urinary cystatin C and tubular proteinuria predict progression of diabetic nephropathy. Diabetes Care. 2013;36(3):656-661

106. Jeon YK, Kim MR, Huh JE, et al. Cystatin C as an early biomarker of nephropathy in patients with type 2 diabetes. $J$ Korean Med Sci. 2011;26(2):258-263

107. Bonventre JV. Kidney injury molecule-1: a translational journey. Trans Am Clin Climatol Assoc. 2014;125:293-299.

108. Petrica L, Vlad A, Gluhovschi G, et al. Proximal tubule dysfunction is associated with podocyte damage biomarkers nephrin and vascular endothelial growth factor in type 2 diabetes mellitus patients: a crosssectional study. PLoS One. 2014;9(11):e112538.

109. Nielsen SE, Sugaya T, Hovind P, Baba T, Parving H-H, Rossing P. Urinary liver-type fatty acid-binding protein predicts progression to nephropathy in type 1 diabetic patients. Diabetes Care. 2010;33(6):1320-1324.

110. Kamijo-Ikemori A, Sugaya T, Yasuda T, et al. Clinical significance of urinary liver-type fatty acid-binding protein in diabetic nephropathy of type 2 diabetic patients. Diabetes Care. 2011;34(3):691-696.

111. Panduru NM, Forsblom C, Saraheimo M, et al; FinnDiane Study Group. Urinary liver-type fatty acid-binding protein and progression of diabetic nephropathy in type 1 diabetes. Diabetes Care. 2013;36(7):2077-2083.

112. Elmarakby AA, Sullivan JC. Relationship between oxidative stress and inflammatory cytokines in diabetic nephropathy. Cardiovasc Ther. 2012;30(1):49-59.

113. Navarro JF, Mora C. Diabetes, inflammation, proinflammatory cytokines, and diabetic nephropathy. ScientificWorldJournal. 2006;6:908-917.

114. Hasegawa G, Nakano K, Sawada M, et al. Possible role of tumor necrosis factor and interleukin-1 in the development of diabetic nephropathy. Kidney Int. 1991;40(6):1007-1012.

115. Ortiz A, González-Cuadrado S, Bustos C, et al. Tumor necrosis factor as a mediator of glomerular damage. J Nephrol. 1995;8:27-34.

116. Bertani T, Abbate M, Zoja C, et al. Tumor necrosis factor induces glomerular damage in rabbit. Am J Pathol. 1989;134(2):419-430.
117. Kalantarinia K, Awas AS, Siragy HM. Urinary and renal interstitial concentrations of TNF- $\alpha$ increase prior to the rise in albuminuria in diabetic rats. Kidney Int. 2003;64(4):1208-1213.

118. Navarro JF, Mora C, Maca M, Garca J. Inflammatory parameters are independently associated with urinary albumin excretion in type 2 diabetes mellitus. Am J Kidney Dis. 2003;42(1):53-61.

119. Navarro JF, Mora C, Rivero A, et al. Urinary protein excretion and serum tumor necrosis factor in diabetic patients with advanced renal failure: effects of pentoxifylline administration. Am J Kidney Dis. 1999;33(3):458-463.

120. Nakamura A, Shikata K, Hiramatsu M, et al. Serum interleukin-18 levels are associated with nephropathy and atherosclerosis in Japanese patients with type 2 diabetes. Diabetes Care. 2005;28(12):2890-2895.

121. Kajitani N, Shikata K, Nakamura A, Nakatou T, Hiramatsu M, Makino H. Microinflammation is a common risk factor for progression of nephropathy and atherosclerosis in Japanese patients with type 2 diabetes. Diabetes Res Clin Pract. 2010;88(2):171-176.

122. Perlman AS, Chevalier JM, Wilkinson P, et al. Serum inflammatory and immune mediators are elevated in early stage diabetic nephropathy. Ann Clin Lab Sci. 2015;45(3):256-263.

123. Har R, Scholey JW, Daneman D, et al. The effect of renal hyperfiltration on urinary inflammatory cytokines/chemokines in patients with uncomplicated type 1 diabetes mellitus. Diabetologia. 2013;56(5):1166-1173.

124. Van Coillie E, Van Damme J, Opdenakker G. The MCP/eotaxin subfamily of chemokines. Cytokine Growth Factor Rev. 1999;10(1):61-86.

125. Tashiro K, Koyanagi I, Saitoh A, et al. Urinary levels of monocyte chemoattractant protein-1 (MCP-1) and interleukin-8 (IL8), and renal injuries in patients with type 2 diabetic nephropathy. JClin Lab Anal. 2002;16(1):1-4.

126. Liu J, Zhao Z, Willcox MD, Xu B, Shi B. Multiplex bead analysis of urinary cytokines of type 2 diabetic patients with normo- and microalbuminuria. J Immunoassay Immunochem. 2010;31(4):279-289.

127. Jiang $\mathrm{H}$, Guan $\mathrm{G}$, Zhang R, et al. Increased urinary excretion of orosomucoid is a risk predictor of diabetic nephropathy. Nephrology. 2009;14(3):332-337.

128. Zoppini G, Targher G, Chonchol M, et al. Predictors of estimated GFR decline in patients with type 2 diabetes and preserved kidney function. Clin J Am Soc Nephrol. 2012;7(3):401-408.

129. Wu LL, Chiou CC, Chang PY, Wu JT. Urinary 8OHdG: a marker of oxidative stress to DNA and a risk factor for cancer, atherosclerosis and diabetics. Clin Chem Acta. 2004;339(1-2):1-9.

130. Hinokio Y, Suzuki S, Hirai M, Suzuki C, Suzuki M, Toyota T. Urinary excretion of 8-oxo-7,8-dihydro-2-deoxyguanosine as a predictor of the development of diabetic nephropathy. Diabetologia. 2002;45(6): $877-882$.

131. Kelly DJ, Aaltonen P, Cox AJ, et al. Expression of the slit-diaphragm protein, nephrin, in experimental diabetic nephropathy: differing effects of antiproteinuric therapies. Nephrol Dial Transplant. 2002;17(7):1327-1332.

132. Langham RG, Kelly DJ, Cox AJ, et al. Proteinuria and the expression of the podocyte slit diaphragm protein, nephrin, in diabetic nephropathy: effects of angiotensin converting enzyme inhibition. Diabetologia. 2002;45(11):1572-1576.

133. Pätäri A, Forsblom C, Havana M, Taipale H, Groop PH, Holthöfer H. Nephrinuria in diabetic nephropathy of type 1 diabetes. Diabetes. 2003;52(12):2969-2974.

134. Ng DP, Tai BC, Tan E, et al. Nephrinuria associates with multiple renal traits in type 2 diabetes. Nephrol Dial Transplant. 2011;26(8): 2508-2514.

135. Kim NH, Kim KB, Kim DL, et al. Plasma and urinary vascular endothelial growth factor and diabetic nephropathy in type 2 diabetes mellitus. Diabet Med. 2004;21(6):545-551.

136. Shoji M, Kobayashi K, Takemoto M, Sato Y, Yokote K. Urinary podocalyxin levels were associated with urinary albumin levels among patients with diabetes. Biomarkers. 2015;21(2):164-167.

137. Turk N, Mornar A, Mrzljak V, Turk Z. Urinary excretion of advanced glycation end products in patients with type 2 diabetes and various stages of proteinuria. Diabetes Metab. 2004;30(2):187-192. 
The International Journal of Nephrology and Renovascular Disease is an international, peer-reviewed open access journal focusing on the pathophysiology of the kidney and vascular supply. Epidemiology, screening, diagnosis, and treatment interventions are covered as well as basic science, biochemical and immunological studies. The manuscript management system is completely online and includes a very quick and fair peer-review system, which is all easy to use. Visit http://www dovepress.com/testimonials.php to read real quotes from published authors.

Submit your manuscript here: https://www.dovepress.com/international-journal-of-nephrology-and-renovascular-disease-journal 